\title{
TRAIL promotes hepatocellular carcinoma apoptosis and inhibits proliferation and migration via interacting with IER3
}

\author{
Shihai Liu', Jing Qiu², Guifang He${ }^{1}$, Weitai He${ }^{3}$, Changchang Liu', Duo Cai and Huazheng Pan ${ }^{3 *}$ (D)
}

\begin{abstract}
Tumor necrosis factor-related apoptosis-inducing ligand (TRAIL) can induce substantial cytotoxicity in tumor cells but rarely exert cytotoxic activity on non-transformed cells. In the present study, we therefore evaluated interactions between TRAIL and IER3 via co-immunoprecipitation and immunofluorescence analyses, leading us to determine that these two proteins were able to drive the apoptotic death of hepatocellular carcinoma (HCC) cells and to disrupt their proliferative and migratory abilities both in vitro and in vivo. From a mechanistic perspective, we determined that TRAIL and IER3 were capable of inhibiting Wnt/ $\beta$-catenin signaling. Together, these results indicate that TRAIL can control the pathogenesis of HCC at least in part via interacting with IER3 to inhibit Wnt/ $\beta$-catenin signaling, thus indicating that this TRAIL/IER3/ $\beta$-catenin axis may be a viable therapeutic target in HCC patients.
\end{abstract}

Keywords: Tumor necrosis factor-related apoptosis-inducing ligand, Wnt pathway, Hepatocellular carcinoma

\section{Introduction}

Hepatocellular carcinoma (HCC) and chronic liver disease $(C L D)$ are increasingly prevalent throughout the world, accounting for 800,000 and 2 million deaths worldwide each year, respectively [1-3]. CLD can additionally drive the development of hepatic scarring, fibrosis, and HCC. Non-alcoholic fatty liver disease (NAFLD) can also promote $\mathrm{HCC}$ development over the course of many years even in the absence of cirrhosis [4]. HCC prevalence in China is particularly high, accounting for $\sim 55 \%$ of global HCC cases [5]. While several diagnostic and therapeutic approaches to detecting and treating HCC have been developed, at present the 5 -year survival rate for those with this disease remains poor and has not improved substantially [6]. It is therefore vital that novel diagnostic biomarkers and therapeutic targets be

*Correspondence: panhuazheng@126.com

${ }^{3}$ Department of Clinical Laboratory, The Affiliated Hospital of Qingdao University, Qingdao 266000, China

Full list of author information is available at the end of the article identified in order to improve the targeted treatment of HCC patients.

TNF-related apoptosis-inducing ligand (TRAIL) is a protein that can induce the apoptotic death of many types of tumor cells, leading many researchers to attempt to develop TRAIL-receptor agonists as a form of anticancer therapy $[7,8]$. Following its secretion from natural killer (NK) cells, TRAIL is capable of binding to cell surface death receptors (DR4 and DR5) [9], after which the pro-form of caspase- 8 is recruited to the Fas-associated death domain (FADD) adaptor protein and is activated, thereby initiating apoptotic signaling cascades that culminate in caspase- 3 activation and cell death [10]. To date, however, DR4/5 agonists and agonistic antibodies specific for these TRAIL receptors have failed to achieve clinical anti-cancer efficacy in phase II clinical trials [11, 12]. This lack of efficacy is generally associated with factors including off-target systemic toxicity, poor agonist bioavailability in tumor tissues, the fact that recombinant TRAIL has a short plasma half-life, and the fact that tumor cells often downregulate DR4/5 or upregulate 
anti-apoptotic proteins to survive [11]. Future research is thus essential in order to overcome these limitations so as to better apply TRAIL-based therapeutics to the treatment of different forms of cancer.

Given that attempts to administer recombinant proteins have failed in this therapeutic context, systemic or intratumoral TRAIL gene transfer therapy has been identified as a potentially viable alternative approach to cancer treatment [13-15]. Several different vectors have been designed and used alone or together with combination chemotherapy to treat cancer by facilitating TRAIL gene transfer with high efficiency, minimal immunogenicity, and little off-target toxicity [16-18]. Gene transfer approaches such as polyethyleneimine (PEI) and other cationic polymers, dendrimers, and liposomes have all been identified as potent approaches to efficient TRAIL gene transfer capable of driving tumor cell apoptosis [16, 19].

Immediate early response gene (IER3), also called IEX1 , is expressed in a wide range of human tissues, including liver tissues [20]. Previous studies have shown that IER3 expression in cancer is significantly reduced [21], and overexpression of IER3 could promote the apoptosis of cancer cells and enhance its sensitivity to chemotherapeutic drugs [22]. In the field of radiation sensitivity of cells, recent studies have found that IER3 gene regulation sequences have radiation induced characteristics [23].

Herein, we employed co-IP approaches to demonstrate an interaction between TRAIL and IER3. We then employed MTT, wound healing, Transwell, and flow cytometry assays to explore the impact of TRAIL and IER3 on tumor cell apoptosis and migratory activity. Furthermore, we utilized an HCC xenograft model system and additional Western blotting to explore the mechanisms whereby these two proteins slow HCC growth in vivo. Overall, our results reveal that TRAIL and IER3 can induce the apoptotic death of HCC cells via influencing the Wnt signaling pathway.

\section{Materials and methods}

Cell culture, transfection, and adenoviral preparation

HEK293, HepG2 and Hep3B cells were obtained from the American Type Culture Collection (ATCC), while BEL7402 and SMMC7721 cells were obtained from the Type Culture Collection of the Chinese Academy of Sciences (Shanghai, China). Huh7 cells were obtained from Procell Life Science \& Technology Co., Ltd. (Wuhan, China). All cells were cultured in RPMI-1640 containing 10\% FBS (Gibco, life technologies, California, USA) and penicillin/streptomycin (Solarbio, beijing China) at $37{ }^{\circ} \mathrm{C}$ in a $5 \% \mathrm{CO}_{2}$ incubator.

In the indicated experiments, cells were transfected with control, TRAIL, or IER3 overexpression vectors using plasmids prepared by GeneChem (Shanghai, China). Briefly, cells were plated in 6-well plates and grown overnight until $70-80 \%$ confluent, at which time Lipofectamine 3000 (Thermo Fisher Scientific, Waltham, MA, USA) was used to transfect cells. At $8 \mathrm{~h}$ post-transfection, media was replaced and cells were cultured for an appropriate time prior to downstream experimentation.

The pAdEasy-1 vector in E. coli BJ5183 was used to prepare recombinant adenoviruses, as in prior studies [24] An appropriate multiplicity of infection was determined by comparing total numbers of infected cells to total plaque-forming units, with duplicate samples being used to titrate prepared adenoviruses to titers of $1 \times 10^{11}$ $\mathrm{pfu} / \mathrm{ml}$.

\section{MTT assay}

Cells were plated in 96-well plates (10,000/well) for an experimentally-determined period of time, after which $10 \mu \mathrm{L}$ of MTT $(5 \mathrm{mg} / \mathrm{mL})$ was added per well followed by an additional $2 \mathrm{~h}$ incubation at $37^{\circ} \mathrm{C}$. Media was then removed, and $100 \mu \mathrm{L}$ of DMSO was added to each well. Absorbance at $490 \mathrm{~nm}$ was then assessed with a microplate reader (model 680, Bio-Rad Laboratories, Hercules, CA). All sample and control samples were analyzed in sextuplicate.

\section{Co-immunoprecipitation (co-IP) and western blotting}

Interactions between IER3 and TRAIL were assessed via co-IP assays. Cells were first lysed using RIPA buffer after being washed with PBS. Lysates were then mixed for $12 \mathrm{~h}$ with appropriate primary antibodies linked to protein A/G sepharose beads (Roche, shanghai, China) at $4{ }^{\circ} \mathrm{C}$ following protein $\mathrm{G}$ sepharose bead pre-clearing. SDS-PAGE was then used to separate precipitated immunocomplexes, and separated proteins were transferred to PVDF membranes (Millipore, Bedford, MA, USA). Blots were then blocked for $2 \mathrm{~h}$ using 5\% non-fat milk in TBST, followed by an overnight incubation with antibodies specific for TRAIL (1:1,000; Santa-Cruz Biotechnology, Santa Cruz, CA, USA), IER3 (1:1,000; Sigma, St. Louis, MO), Myc tag (1:1,000; Sigma, St. Louis, MO), and Flag tag (1:1,000; Cell Signaling, Danvers, MA) at $4{ }^{\circ} \mathrm{C}$. Blots were next washed thrice, followed by incubation for $2 \mathrm{~h}$ with appropriate HRP-linked secondary anti-rabbit and anti-mouse antibodies (1:1,000; Pierce, USA). A Bio-Rad ChemiDoc Imaging System (Bio-Rad, California, USA) was then employed for protein band detection.

\section{GST pulldown}

E. coli BL21(DE3) were initially cultured overnight, after which they were diluted 100-fold in fresh Lysogeny broth (LB) containing $100 \mathrm{mg} / \mathrm{L}$ ampicillin, and were cultured at $37^{\circ} \mathrm{C}$ until racing an OD600 of 0.4-0.6 Recombinant 
GST-fusion protein expression was induced by adding $0.1 \mathrm{mM}$ isopropyl- $\beta$-d-thiogalactoside for $12 \mathrm{~h}$ at $24{ }^{\circ} \mathrm{C}$. Protein was then purified, immobilized on glutathioneagarose (Sigma-Aldrich, St. Louis, MO), and separated via SDS-PAGE to gauge protein amounts. In addition, we expressed Flag-IER3 in E. coli BL21(DE3) and employed a Flag-specific $\mathrm{mAb}$ to purify this protein with an agarose gel (Sino biological, China). GST-fusion proteins were then incubated with a Flag-Select affinity gel precoated with Flag-IER3 for $12 \mathrm{~h}$ at $4{ }^{\circ} \mathrm{C}$ with constant agitation. Beads were then washed extensively with RIPA buffer, after which protein elution and Western blotting were performed.

\section{Immunofluorescent staining}

Huh7 and SMMC7721 HCC cells were cultured in individual wells of 8-well chamber slides (Nunc). Following cell attachment, cells were transfected using pcDNA3TRAIL and/or pcDNA3-IER3, followed by an additional $48 \mathrm{~h}$ incubation. Cells were then washed thrice using PBS, fixed for 15 min with $4 \%$ paraformaldehyde (PFA), permeabilized in $0.1 \%$ Triton $\mathrm{X}-100$ in $\mathrm{PBS} / 3 \% \mathrm{BSA}$ and blocked for $1 \mathrm{~h}$ using 1\% BSA in PBST. Cells were then incubated overnight with an appropriate primary antibody, after which they were washed thrice using PBS and incubated for 30 min with AF488 goat anti-rabbit IgG (Cell Signaling, Danvers, MA, 1:1,000) or AF555 goat anti-mouse IgG (Cell Signaling, Danvers, MA, 1:1,000) at $37^{\circ} \mathrm{C}$. After PBS washing, cells were then stained using DAPI prior to imaging with a Leica TCS SP5 confocal microscope (Leica Microsystems).

\section{Apoptosis and colony formation assays}

A FACSCalibur ${ }^{\mathrm{TM}}$ flow cytometer (BD) was used to evaluate cellular apoptosis after HCC cells had been stained with an Annexin V-PE and 7-AAD Apoptosis Detection kit (Beyotime, Jiangsu, China) based on provided directions. Briefly, cells expressing TRAIL and/or IER3 were harvested during the logarithmic growth phase, stained, and analyzed, with Flowjo being used for data analysis.

For colony formation assays, roughly 1,000 cells/group were resuspended in $10 \mathrm{~mL}$ of RPMI-1640 and were cultured for 10 days until visible colonies were evident. Cells were then fixed for $15 \mathrm{~min}$ with $4 \%$ PFA, and were stained for 20 min using $0.5 \%$ crystal violet. All colonies containing $>50$ cells were then counted under $100 \times$ magnification to quantify the colony-forming abilities of different experimental groups.

\section{Wound healing assay}

Cellular migration was assessed with a wound healing assay. Briefly, cells were cultured in 6-well plates until 90-95\% confluent. Cells were then infected for $24 \mathrm{~h}$ with adenoviruses encoding TRAIL and/or IER3, after which a wound was generated in the cell monolayer using a sterile micropipette tip. Free cells were washed away, and the baseline wound was imaged. Cells were incubated for $24 \mathrm{~h}$ in RPMI-1640 containing 10\% FBS, after which the wound was again imaged at appropriate time points, with cellular migration into the wound site over time thereby being quantified.

\section{In vitro migration assay}

A Transwell 24-well filter insert (Corning, $8.0 \mu \mathrm{m}$ pore size) system was used to evaluate HCC cell migration. Briefly, inserts were treated for 30 min with $200 \mu \mathrm{L}$ of serum-free RPMI- 1640 at $37^{\circ} \mathrm{C}$, after which this media was removed and $600 \mu \mathrm{L}$ of fresh media supplemented with $20 \%$ FBS was added into the lower chamber. Into the upper chamber, cells that had been infected $24 \mathrm{~h}$ previously with Ad5-TRAIL and/or Ad5-IER3 were added $\left(1 \times 10^{5} /\right.$ well $)$ in $100 \mu \mathrm{L}$ of serum-free media. Plates were then incubated for $24 \mathrm{~h}$, after which methanol was used to fix the upper chamber for $30 \mathrm{~min}$, followed by crystal violet staining for an additional hour. Non-migrated cells were then removed from the upper chamber with a cotton swab, and the remaining cells were imaged and counted using an inverted ECLIPSE Ts2 microscope (Nikon, Japan).

\section{In vivo xenograft model}

A murine xenograft model system was used to evaluate the impact of TRAIL/IER3 synergistic effect on HCC tumor growth. All animal experiments were consistent with the National Guidelines for Housing and Care of Laboratory Animals, and were approved by the Institutional Animal Care and Use Committee of the Institute of Medicine, The Affiliated Hospital of Qingdao University. Briefly, female athymic mice (BALB/c nude, 6-8 weeks old, 18-20 g) from Vital River Laboratories (Beijing, China) were subcutaneously implanted with Huh7 or SMMC7721 cells $\left(2 \times 10^{6}\right.$ cells in 100 $\mu \mathrm{L}$ PBS). Tumor growth was monitored every 2 days, with tumor volume $(\mathrm{V})$ being determined as follows: $\mathrm{V}$ $\left(\mathrm{mm}^{3}\right)=0.5 \times \mathrm{a} \times \mathrm{b} \times \mathrm{b}$, where $\mathrm{a}$ and $\mathrm{b}$ correspond to the longest diameter of the tumor and the diameter perpendicular to a, respectively.

When tumors had grown to $50 \mathrm{~mm}^{3}$ in size, animals were randomly assigned to Ad5-EGFP, Ad5-TRAIL, Ad5IER3, and Ad5-TRAIL/Ad5-IER3 groups. Animals in these groups received intratumoral injections of $5 \times 10^{8}$ PFU of the indicated adenovirus in $50 \mu$ PBS once every two days over an 8-day period. After 24 days, mice were then sacrificed via $\mathrm{CO}_{2}$ asphyxiation, and tumors were collected, weighed, imaged, and subjected to pathological analyses [25]. 


\section{TOP/FOP-Flash luciferase reporter analysis}

Wnt $/ \beta$-catenin signaling pathway activity was quantified via a TOP/FOP-Flash luciferase reporter assay, with the pRL-SV40 vector being used as an internal control. Control and NC cells were co-transfected with pRL-SV40 and TOP/FOP flash (Promega, WI, USA). Cells in all groups were co-transfected with pRL-SV40 and TOP/FOP flash, and then treated them for $24 \mathrm{~h}$ with $\mathrm{LiCl}(20 \mathrm{mM})$, with those in the TRAIL + IER3 group additionally being infected with the TRAIL and IER3-encoding adenoviruses. Luciferase activity was then quantified using a Dual-Luciferase Reporter Assay System (Promega, WI, USA), with the TOP/FOP ratio being used to quantify Wnt/ $\beta$-catenin signaling pathway activity following normalization of firefly luciferase activity to Renilla luciferase activity.

we transfected Huh7 cells with the appropriate reporters, and then treated them for $24 \mathrm{~h}$ with $\mathrm{LiCl}(20 \mathrm{mM})$, after which cells were infected with Ad5-TRAIL and Ad5-IER3 or Ad5-EGFP. LiCl treatment was confirmed to increase the TOP/FOP ratio of these HCC cells $(\mathrm{P}<0.01)$, consistent with $\mathrm{Wnt} / \beta$-catenin signaling pathway activation.

\section{Immunohistochemical staining}

The Medical Ethics Committee of Shanghai, China approved the present study. Tissue microarrays that contained $90 \mathrm{HCC}$ tumor tissue samples and 90 paracancerous normal tissue samples (HLivH180Su14) were obtained from Outdo Biotech Co. Ltd. (Shanghai, China), and clinicopathological data pertaining to the patients incorporated into this microarray (including age, sex, tumor stage, tumor grade, tumor size, HBsAg, $\mathrm{HBcAb}, \mathrm{HCV}$ status, and follow-up data) were assessed (Table 1). In addition, diagnosis and staging of the HCC tumor samples within these microarrays were validated internally based upon clinical and pathological evaluation in accordance with the 8th edition of the American Joint Committee on Cancer (AJCC) staging system. No patients included in this study had undergone adjuvant chemotherapy treatment prior to tumor resection.

IER3 expression was assessed via immunohistochemistry (IHC). Briefly, paraffin-embedded tissue Sects. $(5 \mu \mathrm{m}$ thick) were deparaffinized, rehydrated, and treated for 15 min with $10 \mathrm{mM}$ citric acid buffer at $100{ }^{\circ} \mathrm{C}$ to facilitate antigen retrieval. Sections were then probed overnight with primary anti-IER3 (Abcam, Cambridge, CA) at $4{ }^{\circ} \mathrm{C}$, after which they were washed with PBS and probed for $30 \mathrm{~min}$ with an appropriate secondary antibody at $37{ }^{\circ} \mathrm{C}$. After an additional PBS wash, sections were incubated for 2 min with DAB, followed by hematoxylin counterstaining. Slides were then evaluated by three pathologists blinded to patient clinical data. IER3 expression was evaluated by these pathologists based upon staining intensity (scored from 1-4) and on the percentage of IER3-positive cells. Scores ranged from 1 to 4 ( 1 for $0 \%, 2$ for $1-10 \%, 3$ for $11-50 \%$ and 4 for $>50 \%$ ). The amount of these scores was employed to classify the specimens into two groups: 1-2 scores were considered "low" expression, whereas 3-4 scores were considered "high" expression.

\section{Statistical analysis}

All data were analyzed using SPSS v.18.0, while GraphPad Prism 6.0 was employed for figure preparation. Chi-squared tests were used to assess relationships between patient clinicopathological findings and IER3 expression. Spearman's correlation analysis was used to compare associations among analyzed variables. The Kaplan-Meier approach was used to prepare survival curves for the present study, with the log-rank test being employed to assess survival outcome significance. Data are means $\pm S D$, and were compared via Student's t-test or Tukey's post hoc test where appropriate. $\mathrm{P}<0.05$ was the significance threshold.

\section{Results}

\section{Assessment of HCC cell TRAIL sensitivity}

To examine TRAIL-induced inhibition of HCC proliferation, we evaluated using an MTT assay. Briefly, we treated available HCC lines (BEL7402, HepG2, Huh7, Hep3B, and SMMC7721) with a range of doses of soluble TRAIL for a $96 \mathrm{~h}$ period revealing variable TRAIL sensitivity among these cell lines (Fig. 1a). Only the BEL7402 cells were found to be particularly sensitive to TRAIL administration in this context, with the other cell lines all exhibiting some degree of resistance. However, when cells were instead transduced with an adenovirus harboring TRAIL (Ad5-TRAIL), the Huh7, BEL7402, and SMMC7721 cell lines were all found to be sensitive to TRAIL-induced cell growth inhibition in a time-dependent fashion $(\mathrm{P}<0.01)$ (Fig. 1a and Additonal file 1: Fig. S1a).

\section{TRAIL interacts with IER3}

This mode of delivery-dependent variability in TRAIL sensitivity suggests that the direct intracellular delivery of TRAIL via an adenoviral vector may bypass cell surface death receptors, enabling this protein to instead induce apoptosis via interacting with alternative protein targets. To identify potential intracellular TRAIL-interacting proteins, we utilized the NCBI database (https:// www.ncbi.nlm.nih.gov/gene/8743) to identify proteins that can interact with TRAIL. This analysis identified 37 putative interaction targets, including HDAC1, SP1, and RIPK1. To further assess the existence of potential functional associations among these proteins, we 
Table 1 Correlation between IER3 expression and clinicopathologic characteristics of HCC patients

\begin{tabular}{|c|c|c|c|c|c|}
\hline \multirow[t]{2}{*}{ Characteristics IER3 } & \multirow[t]{2}{*}{ No. of cases (\%) } & \multicolumn{4}{|l|}{ IER3 expreesion } \\
\hline & & Low or none, no. cases & High, no. cases & Statistic $\left(c^{2}\right)$ & $p$ value \\
\hline \multicolumn{6}{|l|}{ Age } \\
\hline$<50$ & $37(41.1)$ & 14 & 23 & 1.509 & 0.219 \\
\hline$\geq 50$ & $53(58.9)$ & 27 & 26 & & \\
\hline \multicolumn{6}{|l|}{ Gender } \\
\hline Male & $80(88.9)$ & 37 & 43 & 0.14 & 0.708 \\
\hline Female & $10(11.1)$ & 4 & 6 & & \\
\hline \multicolumn{6}{|l|}{$\mathrm{HBsAg}$} \\
\hline Positive & $70(77.8)$ & 29 & 41 & 2.84 & 0.092 \\
\hline Negative & $19(21.1)$ & 12 & 7 & & \\
\hline \multicolumn{6}{|l|}{$\mathrm{HBCAb}$} \\
\hline Positive & $80(88.9)$ & 35 & 45 & 1.985 & 0.159 \\
\hline Negative & $7(7.8)$ & 5 & 2 & & \\
\hline \multicolumn{6}{|l|}{$\mathrm{HCV}$} \\
\hline Positive & $1(1.1)$ & 0 & 1 & 0.861 & 0.353 \\
\hline Negative & $86(95.6)$ & 40 & 46 & & \\
\hline \multicolumn{6}{|l|}{ Liver cirrhosis } \\
\hline Yes & $80(88.9)$ & 38 & 42 & 0.09 & 0.419 \\
\hline No & $9(10.0)$ & 3 & 6 & & \\
\hline \multicolumn{6}{|l|}{ Total bilirubin (mmol/L) } \\
\hline$<21$ & $75(83.3)$ & 36 & 39 & 0.717 & 0.397 \\
\hline$\geq 21$ & $14(15.6)$ & 5 & 9 & & \\
\hline \multicolumn{6}{|l|}{$\mathrm{ALT}(\mathrm{U} / \mathrm{L})$} \\
\hline$<60$ & $70(77.8)$ & 29 & 41 & 2.84 & 0.092 \\
\hline$\geq 60$ & $19(21.1)$ & 12 & 7 & & \\
\hline \multicolumn{6}{|l|}{ GGT (U/L) } \\
\hline$<40$ & $30(33.3)$ & 9 & 21 & 4.702 & 0.030 \\
\hline$\geq 40$ & $59(65.6)$ & 32 & 27 & & \\
\hline \multicolumn{6}{|l|}{ AFP (ng/L) } \\
\hline$<20$ & $36(40.0)$ & 17 & 19 & 0.067 & 0.795 \\
\hline$\geq 20$ & $54(60.0)$ & 24 & 30 & & \\
\hline \multicolumn{6}{|l|}{ Cirrhotic nodules } \\
\hline Single & $10(11.1)$ & 5 & 5 & 0.653 & 0.765 \\
\hline Multiple & $80(88.9)$ & 36 & 44 & & \\
\hline \multicolumn{6}{|l|}{ Vascular invasion } \\
\hline Yes & $21(23.3)$ & 12 & 9 & 1.545 & 0.214 \\
\hline No & $58(64.4)$ & 24 & 34 & & \\
\hline \multicolumn{6}{|l|}{ Tumor number } \\
\hline Single & $79(87.8)$ & 36 & 43 & 0 & 0.994 \\
\hline Multiple & $11(12.2)$ & 5 & 6 & & \\
\hline \multicolumn{6}{|l|}{ Tumor size } \\
\hline$<5 \mathrm{~cm}$ & $55(61.1)$ & 16 & 39 & 15.458 & $<0.001$ \\
\hline$\geq 5 \mathrm{~cm}$ & $35(38.9)$ & 25 & 10 & & \\
\hline \multicolumn{6}{|l|}{ Recrudescence } \\
\hline Yes & $49(54.4)$ & 27 & 22 & 3.952 & 0.047 \\
\hline No & $41(45.6)$ & 14 & 27 & & \\
\hline \multicolumn{6}{|l|}{ AJCC TNM stage } \\
\hline I stage & $58(64.4)$ & 24 & 34 & 1.392 & 0.499 \\
\hline II stage & $29(32.2)$ & 15 & 14 & & \\
\hline III stage & $3(33.3)$ & 2 & 1 & & \\
\hline
\end{tabular}


Table 1 (continued)

$P$ values were calculated using chi-square test. Italics numbers indicate significant differences $(P<0.05)$

$H C C$ hepatocellular carcinoma, $H B s A g$ hepatitis B surface antigen, $H B C A b$ hepatitis B core antigen, HCV hepatitis C virus, ALT alanine transaminase, GGT GammaGlutamyltransferase, AFP a-fetoprotein, AJCC the American Joint Committee on Cancer, TNM tumor-node-metastasis
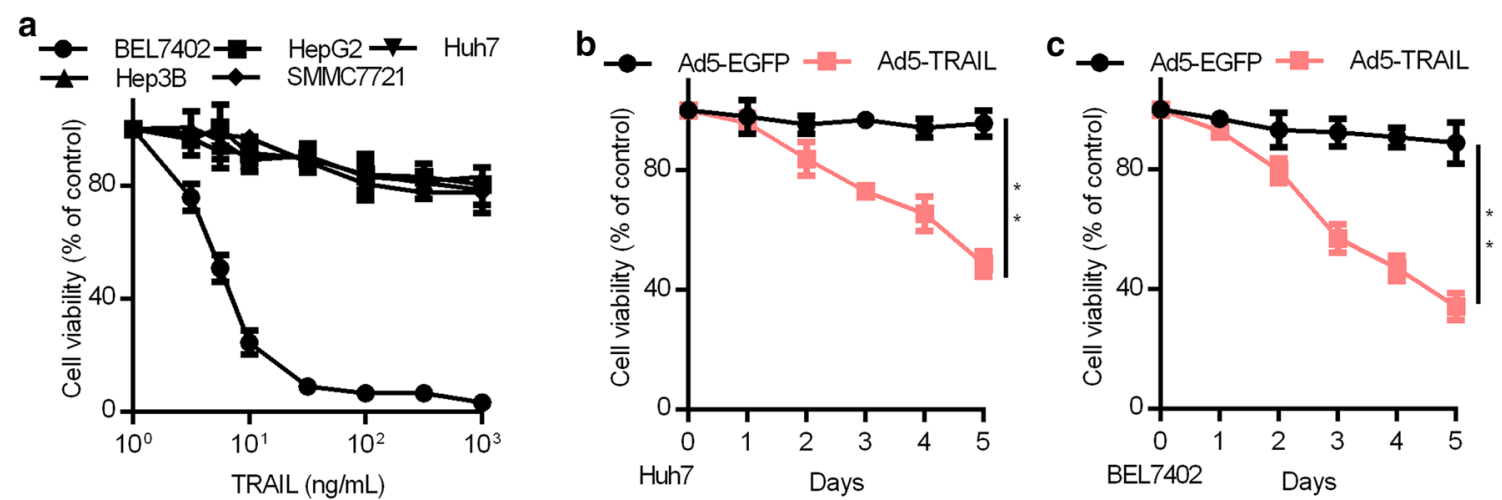

Fig. 1 TRAIL inhibited cell growth in HCC cells. a BEL7402, HepG2, Huh7, Hep3B, and SMMC7721 cells were treated for 96 h using the indicated doses of recombinant human TRAIL, after which growth was assessed via MTT assay. Data are means \pm SD of triplicate samples. Results are the average of three experiments. ${ }^{* *} \mathrm{P}<0.01$, Dunnet's post-hoc test. b, c BEL7402 and Huh7 cells were administered the indicated Ad5-TRAIL doses for the indicated time periods. ${ }^{*} \mathrm{P}<0.01$

queried the STRING (http://string-db.org/) database of known and predicted protein-protein interactions. This analysis revealed that TRAIL can interact with IER3 (Additional file 1: Fig. S1b), indicating that this interaction may be important as a regulator of the survival and proliferative activity of HCC cells. IER3 can regulate a range of processes such as DNA repair, inflammation, proliferation, and apoptosis [21, 26, 27]. In order to confirm that TRAIL can interact with IER3, we next conducted a co-IP assay. Briefly, we first generated IER3-Flag and TRAIL-Myc vectors (Additional file 2: Fig. S2a), after which we directly assessed and confirmed the existence of TRAIL/IER3 interactions within HCC cells (Fig. 2a). We also employed a glutathione S-transferase (GST) pull-down assay approach (Additional file 2: Fig. S2b, c), which further confirmed that GST-TRAIL was capable of interacting with IER3 (Fig. 2b). Immunofluorescent staining of Huh7 and SMMC7721 cells also demonstrated the ability of TRAIL (green) and IER3 (red) to colocalize with one another (Fig. 2c and Additional file 2: Fig. S2d). Together, these findings confirmed that TRAIL can interact with IER3 within HCC cells.

\section{TRAIL and IER3 suppress HCC cell migration and induce apoptotic cell death}

To evaluate the functional impact of TRAIL/IER3 interactions within HCC cells, we next infected Huh7 and
SMMC7721 cell lines with these adenoviral vectors as above and confirmed the efficiency of this infection approach (Additional file 2: Fig. S2e). MTT and colony formation assays were then used to evaluate these cells, revealing that TRAIL and IER3 synergistic effect was associated with reduced viability for both of these cell lines (Fig. 3a, b and Additional file 3: Fig. S3a). An Annexin V-PE/7-AAD dual-staining approach additionally revealed that TRAIL/IER3 synergistic effect induced apoptotic Huh7 and SMMC7721 cell death more readily than did control adenoviral infection (Fig. 3c and Additional file 3: Fig. S3b). In line with these results, we also found TRAIL/IER3 synergistic effect to suppress HCC cell migratory activity in Transwell and wound healing assays (Fig. 3d, e). These findings suggest that TRAIL and IER3 can promote the apoptotic death of HCC cells and can additionally impair the migratory activity of these cells.

\section{TRAIL and IER3 inhibit in vivo HCC cell growth}

We next assessed the ability of TRAIL/IER3 synergistic effect in HCC cells to impact in vivo tumor growth. Briefly, we established an HCC xenograft model by subcutaneously implanting Huh7 cells into athymic nude mice. After 24 days, we found that tumors in which TRAIL and IER3 had been overexpressed were significantly smaller than control tumors in these animals (Fig. 4a, c), consistent with observed differences in tumor growth curves between groups (Fig. 4b). At this day 24 

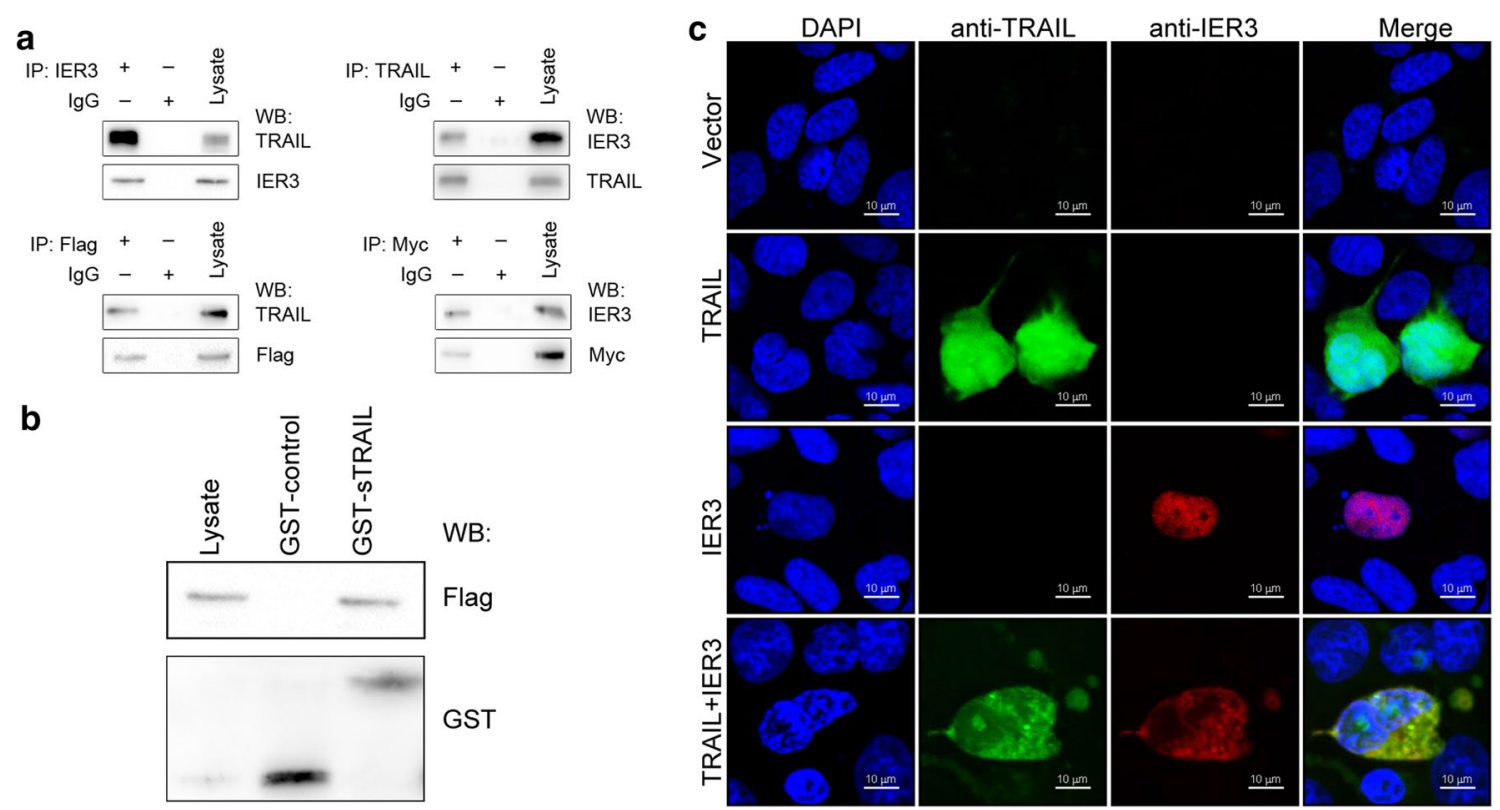

Fig. 2 TRAIL interacts with IER3. a Huh7 cells were co-transfected plasmids encoding Myc-TRAIL and Flag-IER3, after which IER3- or Flag antibody-conjugated beads were used for co-immunoprecipitation (CO-IP) analyses of lysates from these transfected cells. Western blotting was then used to detect TRAIL and IER3 in these samples using appropriate antibodies specific for TRAIL, IER3, Flag, or Myc. For reverse co-IP assays, cells were transfected as above, and then lysates were immunoprecipitated using anti-Myc or anti-TRAIL antibodies, after which TRAIL and IER3 levels in precipitates were measured as above. $\mathbf{b}$ Interactions between GST-TRAIL and IER3 were demonstrated in a GST pulldown assay. c TRAIL-Myc and IER3-Flag localization within Huh7 cells were assessed by fixing cells $24 \mathrm{~h}$ post-transfection, permeabilizing cells, and staining with antibodies specific for TRAIL (green) and IER3 (red), with DAPI (blue) being used to stain nuclei. Cells were then analyzed via confocal microscopy. Scale bars $=10 \mu \mathrm{m}$

time point, we additionally evaluated histopathological findings in these mice and found that TRAIL/IER3 synergistic effect in these tumors was associated with significant reductions in liver metastasis relative to control tumors (Fig. 4d). Comparable findings were also made when mice were instead subcutaneously implanted with SMMC7721 cells (Additional file 4: Fig. S4). These results thus suggest that TRAIL and IER3 upregulation in HCC cells can impair tumor growth and metastasis in vivo.

\section{TRAIL and IER3 inhibit Wnt target gene expression}

Previously, we have discovered that $\mathrm{Wnt} / \beta$-catenin signaling is activated to a greater extent in HCC cells than in normal liver cells [21]. Therefore, we hypothesized that TRAIL/IER3 might target HCC by inhibiting Wnt/ $\beta$ catenin signaling. To assess the impact of TRAIL/IER3 to influence Wnt/ $\beta$-catenin pathway activation, we examined the impact of these proteins in cells that had been stimulated with lithium chloride $(\mathrm{LiCl})$, which is known to activate $\mathrm{Wnt} / \beta$-catenin signaling [28]. To measure $\mathrm{Wnt} / \beta$-catenin signaling activity in this assay context, we assessed the relative luciferase activity of TOPflash and FOPflash reporters (the TOP/FOP ratio) [29]. Briefly, we transfected Huh7 cells with the appropriate reporters, and then treated them for $24 \mathrm{~h}$ with $\mathrm{LiCl}(20 \mathrm{mM})$, after which cells were infected with Ad5-TRAIL and Ad5-IER3 or Ad5-EGFP. LiCl treatment was confirmed to increase the TOP/FOP ratio of these HCC cells $(\mathrm{P}<0.01)$, consistent with $\mathrm{Wnt} / \beta$-catenin signaling pathway activation. Relative to the LiCl-treated control cells, those cells that had been infected with Ad5-TRAIL and Ad5-IER3 exhibited a significant decrease in TOP/FOP ratio values consistent with the suppression of $\mathrm{Wnt} / \beta$-catenin signaling $(\mathrm{P}<0.05)$ (Fig. 5a). To further assess the ability of TRAIL/IER3 to suppress Wnt signaling, we additionally evaluated $\beta$-catenin localization within cells via immunofluorescence. This approach indicated that TRAIL/IER3 synergistic effect was associated with reduced nuclear $\beta$-catenin expression (Fig. 5b). Consistent with these findings, when we employed a Western blotting approach to analyze these cells, we found that TRAIL/IER3 synergistic effect were associated with decreases in nuclear $\beta$-catenin, survivin, and c-Myc protein levels, and with increased PARP expression (Fig. 5c).

\section{IER3 downregulation correlates with HCC prognosis}

IER3 has been shown to control apoptotic cell death in many different physiological contexts [26, 30-32]. In 
a

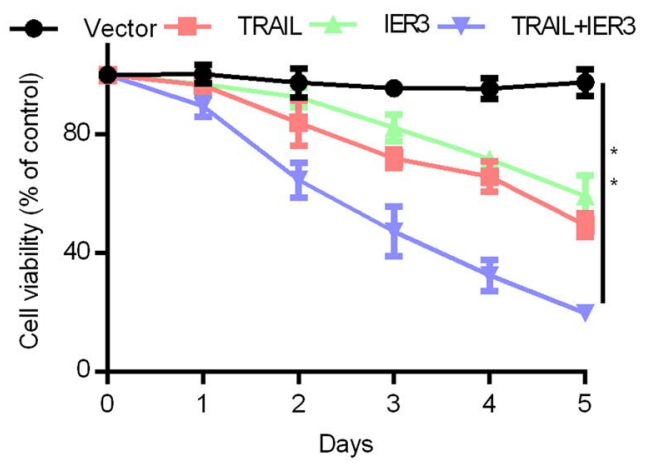

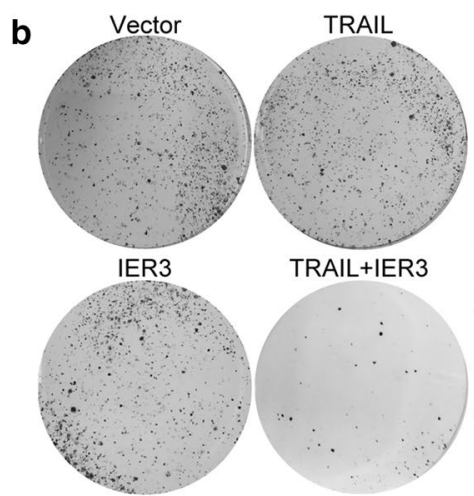

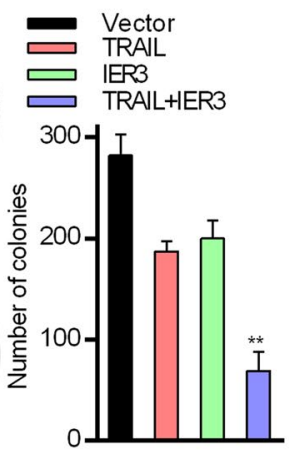

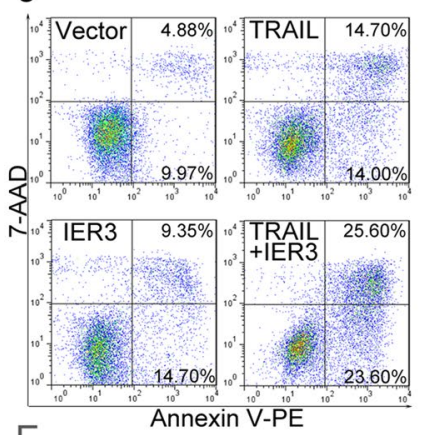
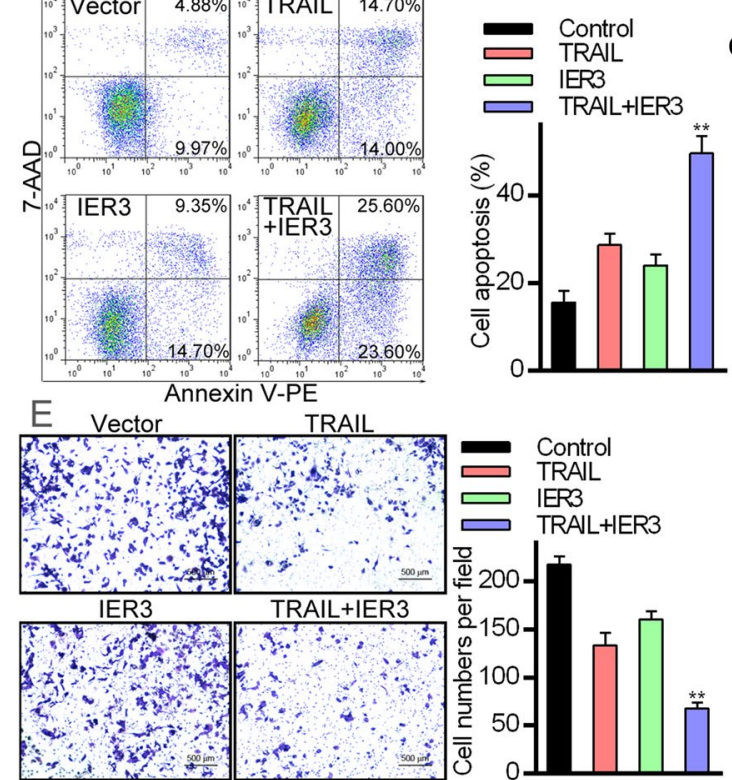

d
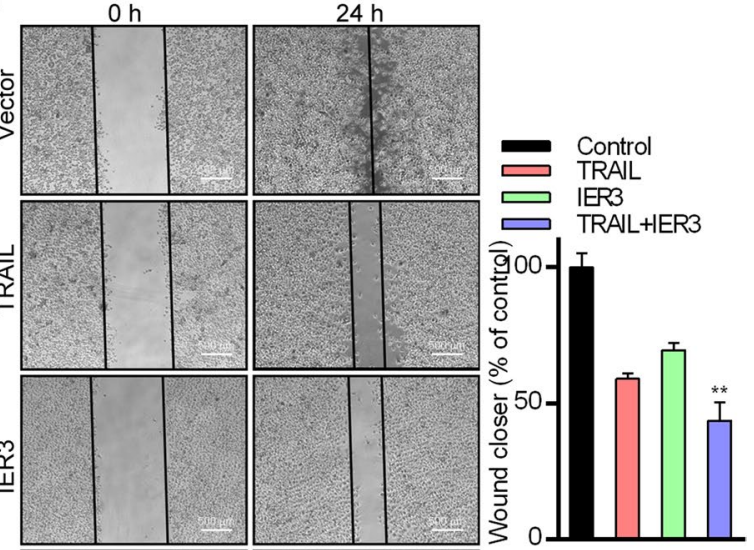

Fig. 3 TRAIL and IER3 suppress HCC cell survival, migration, and colony formation. a Huh7 cells were co-infected with Ad5-TRAIL and Ad5-IER3, after which viability was assessed via MTT assay. b A colony formation assay was employed to assess the viability of cells prepared as in $\mathbf{a}$. c The impact of TRAIL and IER3 synergistic effect on apoptotic cell death in Huh7 cells was evaluated via flow cytometry. $\mathbf{d}$ In a wound healing assay, adenoviral of TRAIL and IER3 synergistic effect was found to suppress Huh7 cell migration. e A Transwell assay was used to assess the migration of cells that had been infected with Ad5-TRAIL or/and Ad5-IER3. Data are means \pm s.d. $\left({ }^{*} P<0.05,{ }^{* *} P<0.01\right)$

order to assess how IER3 expression is associated with HCC patient survival, we examined the expression of this protein via IHC in HCC patient tumor microarrays (TMAs). In total, we analyzed $90 \mathrm{HCC}$ patient tumor and tumor adjacent normal (TAN) tissue samples (Fig. 6a). IER3 staining intensity for these samples was scored from 1-4: 1 (negative), $0 \%$ positive; $2(+), 1-10 \%$ positive; $3(++), 11-50 \%$ positive; $4(+++),>50 \%$ positive (Fig. 6b). In addition, clinicopathological data pertaining to the patients included in this TMA were compiled, including age, gender, $\mathrm{HBsAg}, \mathrm{HBcAb}, \mathrm{HCV}$, liver cirrhosis, total bilirubin level, ALT level, GGT level, cirrhotic nodules, vascular invasion, tumor number, tumor size, recrudescence, and AJCC TNM stage (Table 1).
Patients included in this analysis were between the ages of 31 and 78 (mean: $52.37 \pm 10.76$ years). We analyzed IER3 expression levels in HCC tissues and tumor adjacent normal (TAN) tissues, and IHC analysis revealed that IER3 expression was undetectable or found to be only expressed at low levels in HCC cases compared with TAN (Fig. 6c). When patients were stratified into IER3high or -low groups based upon IHC staining scores, a Kaplan-Meier survival analysis indicated that IER3high patients had a significantly longer overall survival (OS) relative to IER3-low patients (71.43\% vs. 38.09\%) (Fig. 6d). This suggests that IER3 upregulation may be associated with a better prognosis in HCC patients. 


\section{a}

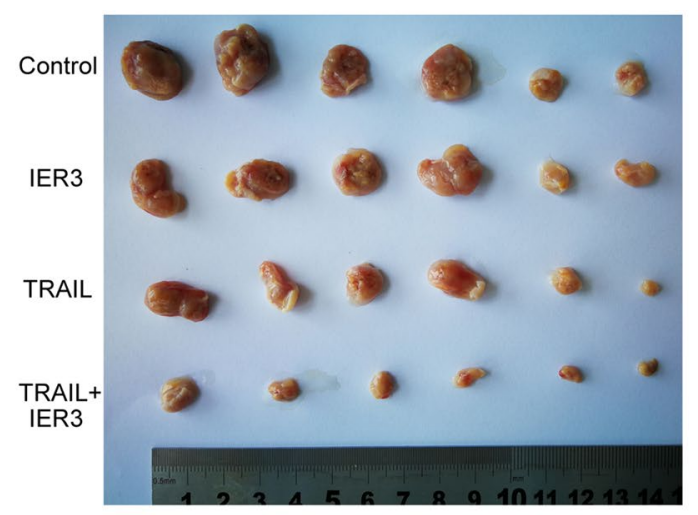

c:

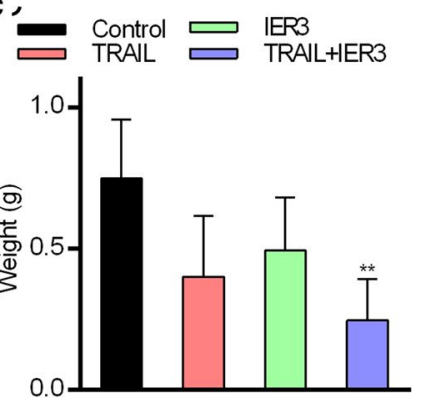

b

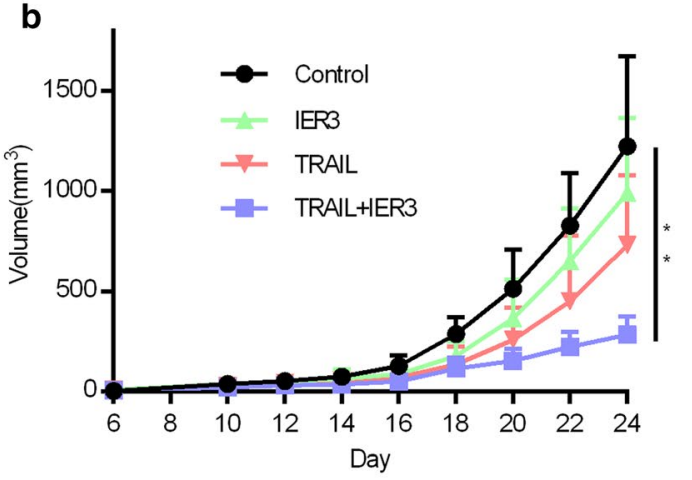

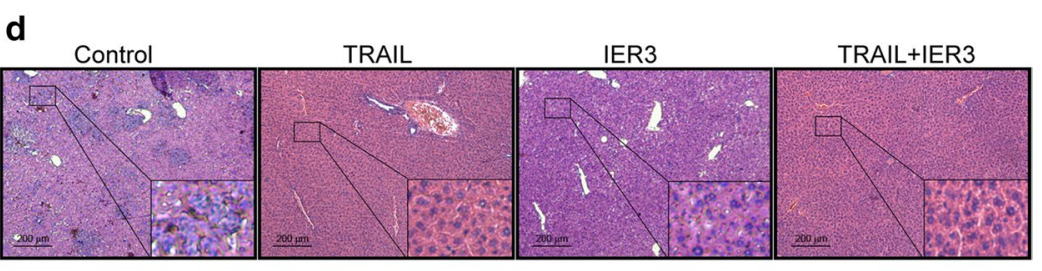

Fig. 4 TRAIL/IER3 synergistic effect inhibits in vivo xenograft Huh7 tumor growth. a On day 24, animals were euthanized and tumors were imaged. b Tumor growth over the 24-day study period. c Tumor weights. $\mathbf{d}$ H\&E staining was used to evaluate tumor histology. Scale bar $=200 \mathrm{~mm}$. ${ }^{* * P}<0.01$

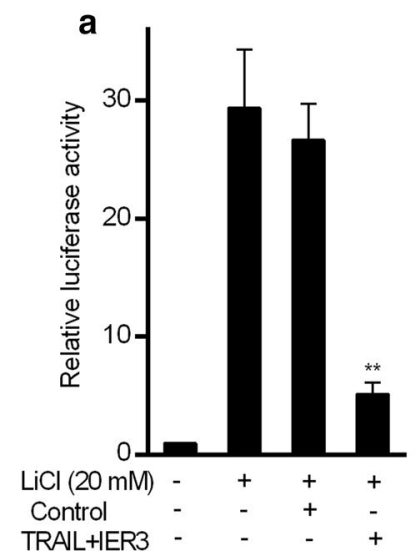

b
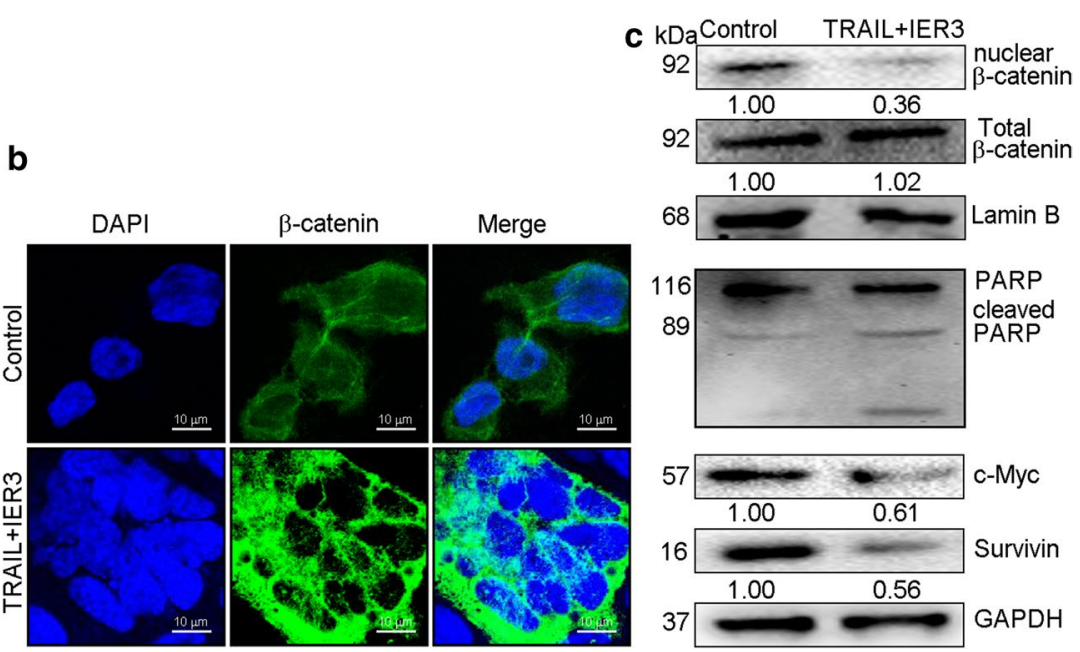

Fig. 5 TRAIL/IER3 inhibit Wnt/ $\beta$-catenin signaling. a After stimulation with LiCl (20 mM), TOP/FOP ratio in a luciferase reporter assay revealed that TRAIL/IER3 synergistic effect impacted Wnt signaling in Huh7 cells. Renilla luciferase activity was used to normalize firefly luciferase activity for all samples, with experiments being repeated three times. ${ }^{* *} \mathrm{P}<0.01$. b, $\mathbf{c}$ Immunofluorescence and Western blotting analysis were used to assess nuclear $\beta$-catenin, PARP, c-Myc, and survivin levels in Huh7 cells following TRAIL/IER3 synergistic effect. Scale bar = $10 \mu \mathrm{m}$

The relationship between IER3 expression and HCC patient clinicopathological features was additionally assessed. We observed a strong relationship between IER3 expression and GGT level $(\mathrm{P}=0.030)$, tumor 


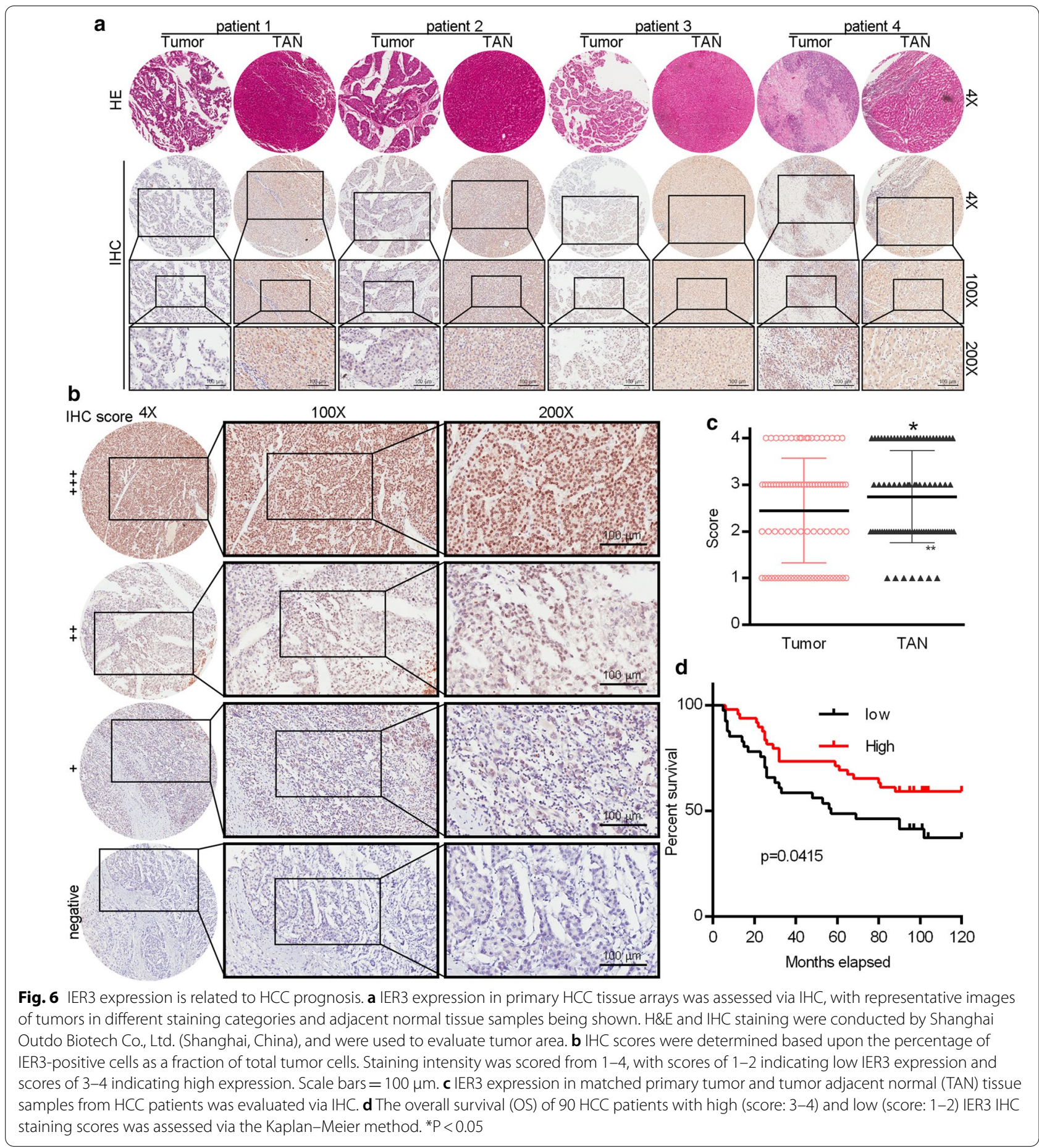

size $(\mathrm{P}<0.001)$, and recrudescence $(\mathrm{P}=0.047)$. In contrast, no relationship between IER3 expression and age $(P=0.219)$, gender $(P=0.708)$, or other clinicopathological features was evaluated (Table 2). We additionally evaluated the relationship between IER3 expression and HCC prognosis via a Cox regression analysis approach, which revealed that IER3 $(\mathrm{P}=0.041), \mathrm{GGT}$ level $(\mathrm{P}=0.034)$, and AJCC TNM stage $(\mathrm{P}=0.021)$ were all significantly associated with HCC patient survival in univariate analyses (Table 3). Subsequent multivariate Cox regression analysis revealed that gender $(\mathrm{P}=0.048)$, HBsAg $(\mathrm{P}=0.037), \mathrm{GGT}(\mathrm{P}=0.017)$, and 
Table 2 Spearman analysis of correlation between TUG1 and clinicopathological

\begin{tabular}{lcc}
\hline Variables & \multicolumn{2}{l}{ IER3 expression level } \\
\cline { 2 - 3 } & $\begin{array}{l}\text { Spearman } \\
\text { correlation }\end{array}$ & p value \\
& -0.129 & 0.224 \\
\hline Age (years, $<50$ vs. $\geq 50$ ) & 0.039 & 0.712 \\
Gender (male/female) & 0.179 & 0.094 \\
HBsAg (positive/negative) & 0.151 & 0.163 \\
HBCAb (positive/negative) & 0.099 & 0.359 \\
HCV (positive/negative) & -0.086 & 0.425 \\
Liver cirrhosis (yes/no) & 0.09 & 0.403 \\
Total bilirubin (mmol/L, <21 vs. $\geq 21)$ & -0.179 & 0.094 \\
ALT (U/L, $<60$ vs. $\geq 60)$ & -0.23 & 0.03 \\
GGT (U/L, <40 vs. $\geq 40)$ & 0.032 & 0.768 \\
Cirrhotic nodules (single/multiple) & -0.14 & 0.219 \\
Vascular invasion (yes/no) & 0.001 & 0.994 \\
Tumor number (single/multiple) & -0.414 & $<0.001$ \\
Tumor size (cm, <5 vs. $\geq 5)$ & -0.21 & 0.047 \\
Recrudescence (yes/no) & -0.079 & 0.461 \\
AJCC TNM stage (I+ II vs III + IV) &
\end{tabular}

Italics numbers indicate significant differences $(P<0.05)$

$H C C$ hepatocellular carcinoma, $H B s A g$ hepatitis B surface antigen, $H B C A b$ hepatitis $B$ core antigen, $H C V$ hepatitis $C$ virus, $A L T$ alanine transaminase, GGT Gamma-Glutamyltransferase, AFP a-fetoprotein, AJCC the American Joint Committee on Cancer, TNM tumor-node-metastasis therapeutic advances, HCC patients still have a poor 5 -year survival rate owing to high rates of tumor metastasis and recurrence [34]. It is thus vital that the molecular mechanisms governing human $\mathrm{HCC}$ be better understood such that it can be more effectively treated.

TRAIL is a type 2 transmembrane protein [35] that can trigger apoptotic cell death [36-38]. TRAIL-induced apoptosis occurs following binding to the DR4 and DR5 receptors, with DR4 binding being thought to be the primary driver of apoptosis [39]. TRAIL binding to these death receptors results in FADD recruitment, which in turn triggers caspase- 8 activation and downstream apoptotic signaling [40-42], although the efficacy of such signaling is dependent upon the glycosylation status of DR4 $[43,44]$ and DR5 $[45,46]$, and on TRAIL multimerization [47-49]. Recent reviews have assessed the potential utility of TRAIL as an anti-tumor agent [35], and the delivery of TRAIL to tumors using alginate-based nanocomposites [50], carbon nanotubes [51], and other inorganic and organic nanoparticles has also been explored $[52,53]$. Adenoviral particles harboring TRAIL have also been shown to be capable of triggering tumor cell apoptosis. However, these prior studies have only evaluated the impact of TRAIL binding to cell surface receptors on apoptotic signaling, and have not explored intracellular mechanisms whereby TRAIL can induce apoptotic cell death.

Table 3 Univariate and multivariate analyses of various prognostic parameters in patients with HCC Cox-regression analysis

\begin{tabular}{|c|c|c|c|c|c|c|}
\hline & \multicolumn{3}{|c|}{ Univariate analysis } & \multicolumn{3}{|c|}{ Multivariate analysis } \\
\hline & $p$ value & Hazard Ratio & $95 \%$ confidence interval & $p$ value & Hazard Ratio & $95 \%$ confidence interval \\
\hline IER3 & 0.041 & 0.549 & $0.305-0.989$ & 0.046252 & 0.596 & $0.246-1.444$ \\
\hline Gender (male/female) & 0.241 & 0.496 & $0.153-1.601$ & 0.048 & 0.168 & $0.029-0.983$ \\
\hline HBsAg (positive/negative) & 0.906 & 1.045 & $0.502-2.175$ & 0.037 & 0.276 & $0.082-0.924$ \\
\hline GGT (U/L, $<40$ vs. $\geq 40)$ & 0.034 & 2.148 & $1.059-4.356$ & 0.017 & 4.274 & $1.300-14.054$ \\
\hline Cirrhotic nodules (single/multiple) & 0.121 & 3.077 & $0.745-12.713$ & 0.033 & 12.069 & $1.216-119.809$ \\
\hline AJCC TNM stage $(I+\|$ vs III + IV) & 0.021 & 4.115 & $1.237-13.688$ & 0.857 & 0.792 & $0.062-10.152$ \\
\hline
\end{tabular}

Italics numbers indicate significant differences $(P<0.05)$

HCC hepatocellular carcinoma, HBsAg hepatitis B surface antigen, GGT Gamma-Glutamyltransferase, AJCC the American Joint Committee on Cancer, TNM tumor-nodemetastasis

cirrhotic nodules $(P=0.033)$ were all predictors of HCC patient survival (Table 3). Together, these results suggest that IER3 expression and other clinicopathological features are associated with HCC patient prognosis.

\section{Discussion}

HCC accounts for over $90 \%$ of liver cancer cases globally, making it one of the most prevalent forms of malignancy in humans [33], with roughly 841,080 new cases and 781,631 deaths worldwide each year [3]. Despite
IER3 is an early response gene family member that is important as a regulator of cellular proliferation and differentiation [54]. It has also been shown to regulate apoptosis in a cell- and stimulus-dependent fashion such that it can either be pro- or anti-apoptotic in specific contexts [23]. Elevated IER3 expression is commonly detected in a range of tumors with a poor prognosis including bladder, breast, pancreatic, and melanoma tumors $[54,55]$. However, there is also evidence that IER3 can promote the apoptotic death of 
HeLa and 293 tumor cells under serum starvation conditions $[26,56]$. The factors that determine whether IER3 functions in a pro- or anti-apoptotic manner in a given context remain to be fully elucidated [26].

To evaluate the mechanisms whereby TRAIL impacts HCC malignancy, we herein evaluated the interactions between TRAIL and other proteins in tumor cells. Through co-IP and immunofluorescence assays, we demonstrated that TRAIL can interact with IER3 in the cytoplasm and nucleus of HCC cells. We further found that TRAIL and IER3 can induce apoptotic cell death and can suppress the migration and proliferation of these HCC cells. Indeed, in MTT assays we found that TRAIL/IER3 synergistic effect was associated with reduced HCC cell viability relative to the overexpression of TRAIL or IER3 alone. This was consistent with Annexin V/PI staining results and migration assays, which revealed that TRAIL/IER3 synergistic effect was associated with significantly enhanced apoptotic death and impaired migration as compared to the overexpression of TRAIL or IER3 alone. We additionally observed differences in Wnt pathway activation and target gene expression in HCC cells following TRAIL/IER3 synergistic effect, suggesting that these proteins can inhibit Wnt pathway signaling. Together, these findings suggest that TRAIL/IER3 serves as a critical protein-protein signaling complex in HCC cells.

\section{Conclusions}

The results of the present study demonstrate that TRAIL is able to directly interact with IER3, and that both of these proteins are important inhibitors of HCC progression. TRAIL and IER3 synergistic effect can inhibit the proliferation and migratory activity of HCC cells, while also inducing their apoptotic death. This TRAIL/IER3 axis may therefore be a viable therapeutic target for the treatment of HCC, although further research will be necessary to validate this hypothesis and to evaluate the molecular mechanisms whereby these proteins govern $\mathrm{HCC}$ onset and progression.

\section{Supplementary Information}

The online version contains supplementary material available at https://doi. org/10.1186/s12935-020-01724-8.

Additional file 1: Fig. S1. The impact of TRAIL-expression on HCC cells. a SMMC7721 cells were infected with Ad5-TRAIL at the indicated doses for a range of time periods. ${ }^{*} \mathrm{P}<0.01$. b Functional associations among TRAIL target genes. All 37 of these putative interacting genes were uploaded into the STRING database (http://string-db.org/), and TRAIL-related protein interaction networks were then evaluated.

Additional file 2: Fig. S2. TRAIL interacts with IER3. a IER3-Flag and TRAILMyc vector maps. b IER3-Flag and GST-TRAIL vector maps. c The GST-TRAIL fusion protein was purified and precipitated using glutathione-agarose via SDS-PAGE with gel staining. d TRAIL (green) and IER3 (red) colocalization in SMMC7721 cells was assessed via immunofluorescent staining. Scale bar $=10 \mu \mathrm{m}$. e Ad5-TRAIL and Ad5-IER3 infection of Huh7 and SMMC7721 cells. Scale bar $=100 \mu \mathrm{m}$.

Additional file 3: Fig. S3. TRAIL and IER3 suppress HCC cell survival, migration, and colony formation. a SMMC7721 cells were co-infected with Ad5-TRAIL and Ad5-IER3, after which a colony formation assay was employed to assess the viability of these cells. $\mathbf{b}$ The impact of TRAIL and IER3 synergistic effect on apoptotic cell death in SMMC7721 cells was evaluated via flow cytometry. c In a wound healing assay, adenoviral overexpression of TRAIL and IER3 was found to suppress SMMC7721 cell migration. $\mathbf{d}$ A Transwell assay was used to assess the migration of cells that had been infected with Ad5-TRAIL or/and Ad5-IER3. Data are means \pm sd. $\left({ }^{*} P<0.05,{ }^{* *} \mathrm{P}<0.01\right)$.

Additional file 4: Fig. S4. TRAIL and IER3 suppress HCC cell survival, migration, and colony formation. a SMMC7721 cells were co-infected with Ad5-TRAIL and Ad5-IER3, after which a colony formation assay was employed to assess the viability of these cells. $\mathbf{b}$ The impact of TRAIL and IER3 synergistic effect on apoptotic cell death in SMMC7721 cells was evaluated via flow cytometry. $\mathbf{c}$ In a wound healing assay, adenoviral overexpression of TRAIL and IER3 was found to suppress SMMC7721 cell migration. $\mathbf{d}$ A Transwell assay was used to assess the migration of cells that had been infected with Ad5-TRAIL or/and Ad5-IER3. Data are means \pm sd. $\left({ }^{*} P<0.05,{ }^{* *} P<0.01\right)$.

\section{Acknowledgements}

We appreciate researchers who have developed and maintained public databases such as GEPIA, UALCAN, and LinkedOmics which will accelerate the understanding and treatment of human cancer.

\section{Authors' contributions}

SHL conceived and together with WTH and HZP designed the study. JQ, GFH and CCL were involved in data collection. DC and CCL performed the statistical analysis and preparation of figures. BT drafted the paper. SHL, JQ, WTH and GFH contributed substantially to its revision. All authors read and approved the final manuscript.

\section{Funding}

This manuscript is supported by the National Natural Science Foundations of China (81402579); the Program for Key research and development plan of Shandong province (2017GSF18179); the Source Innovation Plan of Qingdao (18-2-2-79-jch). This project was sponsored by Youth foundation of the affiliated hospital of medical college, Qingdao University (AHMCQ201232).

\section{Availability of data and materials}

The datasets generated and/or analyzed during the current study are available from the corresponding author on reasonable request.

\section{Ethics approval and consent to participate}

The study was conducted with the approval of the Ethics Committee of the Affiliated Hospital of Qingdao University. All participating patients provided written informed consent. Nude mice used for in vivo experimental animal studies were cared for in accordance with a protocol approved by the Laboratory Animal Care and Use Committee of the Affiliated Hospital of Qingdao University (AHQU20180822A).

\section{Consent for publication}

Not applicable.

\section{Competing interest}

The authors declare that they have no competing interests.

\section{Author details}

${ }^{1}$ Medical Animal Lab, The Affiliated Hospital of Qingdao University, Qingdao 266000, China. ${ }^{2}$ Department of Stomatology, Qingdao Municipal Hospital, Qingdao 266071, China. ${ }^{3}$ Department of Clinical Laboratory, The Affiliated Hospital of Qingdao University, Qingdao 266000, China. 
Received: 29 June 2020 Accepted: 19 December 2020

Published online: 20 January 2021

\section{References}

1. Asrani SK, et al. Burden of liver diseases in the world. J Hepatol. 2019;70(1):151-71.

2. Liu Z, et al. The trends in incidence of primary liver cancer caused by specific etiologies: Results from the Global Burden of Disease Study 2016 and implications for liver cancer prevention. J Hepatol. 2019:70(4):674-83.

3. Bray F, et al. Global cancer statistics 2018: GLOBOCAN estimates of incidence and mortality worldwide for 36 cancers in 185 countries. CA Cancer J Clin. 2018;68(6):394-424.

4. Berentzen $T L$, et al. Body mass index in childhood and adult risk of primary liver cancer. J Hepatol. 2014;60(2):325-30.

5. Muller $\mathrm{M}$, et al. The landscape of gene mutations in cirrhosis and hepatocellular carcinoma. J Hepatol. 2020;72(5):990-1002.

6. Kee KM, et al. Hepatocellular carcinoma associated with extra-hepatic primary malignancy: its secular change. Clinical Manifestations Survival Sci Rep. 2016;6:30156.

7. Falschlehner C, et al. TRAIL and other TRAIL receptor agonists as novel cancer therapeutics. Adv Exp Med Biol. 2009;647:195-206.

8. de Miguel D, et al. Onto better TRAILs for cancer treatment. Cell Death Differ. 2016;23(5):733-47.

9. Zamai L, et al. Natural killer (NK) cell-mediated cytotoxicity: differential use of TRAIL and Fas ligand by immature and mature primary human NK cells. J Exp Med. 1998;188(12):2375-80.

10. Huang Y, et al. Overcoming resistance to TRAlL-induced apoptosis in solid tumor cells by simultaneously targeting death receptors, C-FLIP and IAPS. Int J Oncol. 2016:49(1):153-63.

11. Lemke J, et al. Getting TRAIL back on track for cancer therapy. Cell Death Differ. 2014:21(9):1350-64.

12. Holland PM. Death receptor agonist therapies for cancer, which is the right TRAIL? Cytokine Growth Factor Rev. 2014;25(2):185-93.

13. Zhou W, et al. Telomerase-specific oncolytic adenovirus expressing TRAIL suppresses peritoneal dissemination of gastric cancer. Gene Ther 2017;24(4):199-207.

14. Griffith TS, et al. TRAIL gene therapy: from preclinical development to clinical application. Curr Gene Ther. 2009;9(1):9-19.

15. Miao L, et al. Targeting tumor-associated fibroblasts for therapeutic delivery in desmoplastic tumors. Cancer Res. 2017:77(3):719-31.

16. Wang Y, et al. Triazine-modified dendrimer for efficient TRAIL gene therapy in osteosarcoma. Acta Biomater. 2015;17:115-24.

17. Lin T, et al. Combination of TRAIL gene therapy and chemotherapy enhances antitumor and antimetastasis effects in chemosensitive and chemoresistant breast cancers. Mol Ther. 2003;8(3):441-8.

18. Luo C, et al. A novel cationic lipid with intrinsic antitumor activity to facilitate gene therapy of TRAIL DNA. Biomaterials. 2016;102:239-48.

19. Zhan C, et al. Co-delivery of TRAIL gene enhances the anti-glioblastoma effect of paclitaxel in vitro and in vivo. J Control Release. 2012;160(3):630-6.

20. Emma MR, et al. NUPR1, a new target in liver cancer: implication in controlling cell growth, migration, invasion and sorafenib resistance. Cell Death Dis. 2016:7(6):e2269.

21. Jin $\mathrm{H}$, et al. Scaffold protein FHL2 facilitates MDM2-mediated degradation of IER3 to regulate proliferation of cervical cancer cells. Oncogene. 2016;35(39):5106-18.

22. Jin $\mathrm{H}$, et al. IER3 is a crucial mediator of TAp73beta-induced apoptosis in cervical cancer and confers etoposide sensitivity. Sci Rep. 2015;5:8367.

23. Schilling $D$, et al. IEX-1, an immediate early gene, increases the rate of apoptosis in keratinocytes. Oncogene. 2001;20(55):7992-7.

24. Liu S, et al. Genetically modified adenoviral vector with the protein transduction domain of Tat improves gene transfer to CAR-deficient cells. Biosci Rep. 2009;29(2):103-9.

25. Liu S, et al. LncRNA MALAT1 acts as a miR-125a-3p sponge to regulate FOXM1 expression and promote hepatocellular carcinoma progression. J Cancer. 2019:10(26):6649-59.

26. Arlt A, et al. Expression of the NF-kappa B target gene IEX-1 (p22/PRG1) does not prevent cell death but instead triggers apoptosis in Hela cells. Oncogene. 2001;20(1):69-76.
27. Sebens Muerkoster $\mathrm{S}$, et al. The apoptosis-inducing effect of gastrin on colorectal cancer cells relates to an increased IEX-1 expression mediating NF-kappa B inhibition. Oncogene. 2008;27(8):1122-34.

28. Klein PS, et al. A molecular mechanism for the effect of lithium on development. Proc Natl Acad Sci U S A. 1996:93(16):8455-9.

29. Korinek V, et al. Constitutive transcriptional activation by a beta-cateninTcf complex in APC-/- colon carcinoma. Science. 1997:275(5307):1784-7.

30. Arlt A, et al. IEX-1 directly interferes with RelA/p65 dependent transactivation and regulation of apoptosis. Biochim Biophys Acta. 2008;1783(5):941-52

31. Ishimoto Y, et al. IEX-1 suppresses apoptotic damage in human intestinal epithelial Caco-2 cells induced by co-culturing with macrophage-like THP-1 cells. Biosci Rep. 2011;31(5):345-51.

32. Kumar $\mathrm{R}$, et al. Immediate early gene $X-1$ interacts with proteins that modulate apoptosis. Biochem Biophys Res Commun. 2004;323(4):1293-8.

33. Llovet JM, et al. Hepatocellular carcinoma. Nat Rev Dis Primers. 2016;2:16018

34. El-Serag HB. Hepatocellular carcinoma. N Engl J Med. 2011;365(12):1118-27.

35. Belkahla $\mathrm{H}$, et al. TRAIL-NP hybrids for cancer therapy: a review. Nanoscale. 2017;9(18):5755-68

36. Jacquemin $\mathrm{G}$, et al. Quercetin-mediated $\mathrm{Mcl}-1$ and survivin downregulation restores TRAIL-induced apoptosis in non-Hodgkin's lymphoma B cells. Haematologica. 2012;97(1):38-46.

37. Jacquemin $\mathrm{G}$, et al. Combining naturally occurring polyphenols with TNFrelated apoptosis-inducing ligand: a promising approach to kill resistant cancer cells? Cell Mol Life Sci. 2010;67(18):3115-30.

38. Micheau $\mathrm{O}$, et al. Death receptors as targets in cancer. Br J Pharmacol. 2013:169(8):1723-44

39. Dufour F, et al. TRAIL receptor gene editing unveils TRAIL-R1 as a master player of apoptosis induced by TRAIL and ER stress. Oncotarget. 2017;8(6):9974-85.

40. Elmallah Ml, et al. Marine drugs regulating apoptosis induced by tumor necrosis factor-related apoptosis-inducing ligand (TRAIL). Mar Drugs. 2015;13(11):6884-909.

41. Constantinescu AA, et al. Immunoprecipitation of death inducing signaling complex by caspase-8. Methods Mol Biol. 2017;1557:19-31.

42. Elmallah MIY, et al. Marine actinomycete crude extracts with potent TRAIL-resistance overcoming activity against breast cancer cells. Oncol Rep. 2017;37(6):3635-42.

43. Dufour F, et al. N-glycosylation of mouse TRAIL-R and human TRAIL-R1 enhances TRAll-induced death. Cell Death Differ. 2017:24(3):500-10.

44. Alkurdi $L$, et al. Release of c-FLIP brake selectively sensitizes human cancer cells to TLR3-mediated apoptosis. Cell Death Dis. 2018;9(9):874.

45. Wagner KW, et al. Death-receptor O-glycosylation controls tumorcell sensitivity to the proapoptotic ligand Apo2L/TRAIL. Nat Med. 2007:13(9):1070-7.

46. Micheau O. Regulation of TNF-Related Apoptosis-Inducing Ligand Signaling by Glycosylation. Int J Mol Sci. 2018; 19(3).

47. Chekkat N, et al. Relationship between the agonist activity of synthetic ligands of TRAIL-R2 and their cell surface binding modes. Oncotarget. 2018;9(21):15566-78

48. De Miguel D, et al. High-order TRAIL oligomer formation in TRAIL-coated lipid nanoparticles enhances DR5 cross-linking and increases antitumour effect against colon cancer. Cancer Lett. 2016;383(2):250-60.

49. Berg $D$, et al. Enforced covalent trimerization increases the activity of the TNF ligand family members TRAIL and CD95L. Cell Death Differ. 2007:14(12):2021-34

50. Cui W, et al. Fabrication of tumor necrosis factor-related apoptosis inducing ligand (TRAIL)/ALG modified $\mathrm{CaCO} 3$ as drug carriers with the function of tumor selective recognition. J Mater Chem B. 2013;1(9):1326-32.

51. Zakaria $A B$, et al. Nanovectorization of TRAIL with single wall carbon nanotubes enhances tumor cell killing. Nano Lett. 2015;15(2):891-5.

52. Perlstein $B$, et al. TRAIL conjugated to nanoparticles exhibits increased anti-tumor activities in glioma cells and glioma stem cells in vitro and in vivo. Neuro Oncol. 2013;15(1):29-40.

53. Kim H, et al. A sulfate polysaccharide/TNF-related apoptosis-inducing ligand (TRAIL) complex for the long-term delivery of TRAIL in poly(lactic-co-glycolic acid) (PLGA) microspheres. J Pharm Pharmacol. 2013:65(1):11-21 
54. Garcia MN, et al. IER3 supports KRASG12D-dependent pancreatic cancer development by sustaining ERK1/2 phosphorylation. J Clin Invest. 2014;124(11):4709-22.

55. Ye J, et al. Increased expression of immediate early response gene 3 protein promotes aggressive progression and predicts poor prognosis in human bladder cancer. BMC Urol. 2018;18(1):82.

56. Grobe $\mathrm{O}$, et al. Functional disruption of IEX-1 expression by concatemeric hammerhead ribozymes alters growth properties of 293 cells. FEBS Lett. 2001;494(3):196-200.

\section{Publisher's Note}

Springer Nature remains neutral with regard to jurisdictional claims in published maps and institutional affiliations.
Ready to submit your research? Choose BMC and benefit from:

- fast, convenient online submission

- thorough peer review by experienced researchers in your field

- rapid publication on acceptance

- support for research data, including large and complex data types

- gold Open Access which fosters wider collaboration and increased citations

- maximum visibility for your research: over $100 \mathrm{M}$ website views per year

At BMC, research is always in progress.

Learn more biomedcentral.com/submissions 